\title{
¿Por qué la religión "regresó" a la esfera pública en un mundo secularizado?
}

\author{
Roberto J. Blancarte \\ El Colegio de México \\ blancart@colmex.mx
}

\section{Resumen}

La secularización, entendida como la pérdida de influencia de lo religioso en la vida pública y en la vida cotidiana de las personas, no es un fenómeno que excluye el "regreso" de la religión en la escena política internacional, así como en la vida de las naciones. Lo que este texto pretende mostrar es que ambos fenómenos, aunque contradictorios, pueden coexistir, si bien generando tensiones. La clave para este aparente dilema radica en dos cuestiones centrales: la definición de los procesos que estamos tratando de explicar, es decir secularización y laicidad, así como la interrelación entre ambos conceptos.

Palabras clave: secularización, laicidad, religión, esfera pública.

\section{Abstract}

Secularity, or the loss of influence from the religious sphere onto the public sphere and everyday life, is not a phenomenon that excludes the reinstatement of religion 
into the international political scene or into the life of nations. This article attempts to demonstrate that these seemingly contradictory phenomena can coexist, although they might create tensions. The key to solve this apparent dilemma can be found in the definition to the processes we are trying to explain, secularity and laicity, and the relationship between both concepts.

Keywords: secularity, laicity, religion, public sphere.

Los estudiosos del fenómeno religioso, que suelen ser los mismos que han diseñado y construido el paradigma de la secularización, han debatido durante décadas acerca del papel de la religión en la esfera pública. Muchos insistieron en la pérdida de influencia de lo religioso en la vida pública y en la vida cotidiana de las personas. Otros han constatado el "regreso" de la religión en la escena política internacional, así como en la vida de las naciones. Cada uno de estos bandos ha insistido en su explicación y ha desdeñado o minimizado la otra. Mientras que algunos muestran, con sólidos argumentos, la pérdida de influencia de las religiones en el mundo, sobre todo el occidental pero no únicamente, otros se esfuerzan en señalar, con fuertes evidencias, la presencia de la religión en la esfera política y en las acciones del Estado. Sin embargo, ninguno de ellos ha intentado establecer una argumentación coherente que explique la simultaneidad de ambos fenómenos. Quizás porque al asumir que son procesos contradictorios, les parece que también tendrían que ser excluyentes. Lo que intentaremos hacer en este texto es, por el contrario, mostrar que ambos fenómenos, aunque contradictorios, pueden coexistir, si bien generando tensiones. Para lograrlo proponemos una combinación, después de un análisis exhaustivo, de dos conceptos clave: secularización y laicidad. Desde nuestra perspectiva, la combinación de ambos conceptos nos permitiría explicar entonces lo que a simple vista aparece como un fenómeno por lo menos paradójico: que el "regreso" (que para nosotros es permanencia) de la religión a la esfera pública, sucede al mismo tiempo que la sociedad (y no sólo la occidental) se sigue secularizando.

La mayor parte de los estudiosos del fenómeno de la secularización fueron incapaces de pensar que las dos cosas podían suceder simultáneamente y no necesariamente como residuos del pasado entre las sociedades tradicionales o, por el contrario, como excepciones por la trayectoria específica de algunas sociedades occidentales, sino como parte de un todo que acontece en distintas esferas y a diversos niveles. No se trata entonces de explicar en tanto que anomalías o "casos sui generis" lo que para algunos es una resistencia a una ineluctable desaparición y para otros la presencia inevitable del fenómeno religioso. En otras palabras, la secularización social sucede al 
mismo tiempo que la religión "regresa", y con fuerza, a la esfera pública. No hay contradicción en ello.

¿Cómo puede existir por un lado un proceso que implica la disminución del papel de la religión en la vida de las personas, al mismo tiempo que, por el otro, las religiones se insertan en la esfera política, impactando las vidas de las personas? ¿Cómo entender, por ejemplo, lo que está sucediendo en una región como América Latina, donde los procesos de secularización (entendidos como la disminución de la influencia religiosa en la sociedad) tienen lugar al mismo tiempo que observamos una creciente intervención e influencia política de la Iglesia católica y en algunos casos (Brasil, Perú, Chile) de las Iglesias evangélicas? Se trata de procesos sociales que tienen lugar en distintas esferas sociales y que más bien generan una tensión permanente, que a su vez es resuelta de manera diversa de acuerdo con las trayectorias nacionales y regionales específicas.

La clave para este aparente dilema radica en dos cuestiones centrales. En primer lugar la definición de los procesos que estamos tratando de explicar: secularización y laicidad. En segundo lugar y no menos importante que lo primero: la interrelación entre dos conceptos que permiten explicar por qué, al mismo tiempo que las sociedades avanzan en sus procesos de secularización, conocen un fuerte retorno de las religiones en los espacios públicos.

\section{¿Qué es y qué no es la secularización?}

Quizás sería más útil comenzar con una definición negativa: lo que la secularización no es. Muchos de los equívocos académicos e intelectuales que han surgido alrededor de este tema se basan en una concepción distorsionada de lo que es dicho proceso. Y sin embargo los especialistas ya lo han señalado desde hace varias décadas: la secularización no significa la desaparición de la religión de la vida de los seres humanos. Por lo tanto, tampoco de su influencia en las distintas esferas en las que ésta se desenvuelve. Ni Weber ni Durkheim, grandes especialistas de la religión, pretendieron que la religión estaba desapareciendo. Todo lo contrario. Weber se dedicó a explicar la importancia de la religión cristiana en el desarrollo del capitalismo y mostró que la religión, contrariamente a la magia, era una gran fuerza racionalizadora del mundo. Durkheim, por su parte, mostró que la religión era esencial para la vida social de todos los pueblos y que, por lo tanto, ésta se transformaría, pero continuaría estando en el centro de las necesidades de sobrevivencia de cualquier sociedad, creándose y recreándose a través de lo ideal. Ninguno de ellos predijo por tanto la desaparición de la religión. En to- 
do caso, anunciaron su creciente racionalización y su transformación en formas menos tradicionales, como la "religión civil". ${ }^{1}$ Fueron más bien los sociólogos norteamericanos posteriores a ellos quienes crearon el mito de la secularización, como algo ineluctable que ya estaba sucediendo en las sociedades occidentales y que, de ser el caso, eventualmente tendría lugar en otras regiones del mundo. Fenómeno que ellos ligaban a la industrialización y la urbanización, así como a una vertiente subjetiva; es decir, una secularización de las conciencias, lo cual significaba esencialmente una salida de la esfera pública. Parsons, Berger y David Martin se sitúan en esta manera de comprender la secularización, en tanto que fenómeno occidental susceptible de extenderse a otras latitudes, cuya característica principal sería el debilitamiento, si no es que la desaparición, de los sistemas de significado religiosos y su sustitución por sistemas de sentido inmanentes. ${ }^{2}$

Esta manera de concebir la secularización entró en crisis hacia finales de la década de los años setenta del siglo XX, más por la obvia reaparición del fenómeno religioso en la vida pública que por cuestionamientos académicos. La revolución islámica de Irán y otros acontecimientos políticos relevantes a nivel internacional, desde la teología de la liberación hasta la nueva derecha cristiana en Estados Unidos, pasando por el conflicto entre Israel y Palestina o en Irlanda del Norte, habrían de mostrar la relevancia del fenómeno religioso. Posteriormente los académicos comenzaron a reaccionar y a replantear el tema de la secularización de forma distinta, no ya como un fenómeno (el religioso) en vías de desaparición, sino como un proceso más complejo en el que la religión se estaría transformando en una época de creciente incertidumbre ante el propio fracaso de las utopías del creciente racionalismo y progreso.

Para algunos autores, como Danièle Hervieu-Léger el problema central de la interpretación del fenómeno de la secularización era el postulado fundador de la sociología de las religiones, el cual había establecido una incompatibilidad esencial entre la religión y la racionalidad moderna. Pero los nuevos movimientos religiosos serían la muestra de que, a través de una

${ }^{1}$ Obviamente estoy haciendo referencia a los diversos textos de Max Weber sobre sociología de la religión, en particular sus tres volúmenes titulados Gesammelte Aufsätze zur Religionssoziologie (Weber, 1988), traducidos al español como Ensayos sobre sociología de la religión, y los textos sobre el tema incluidos en Economía y sociedad (Weber, 2014). Respecto a Émile Durkheim, me baso en su postrero libro Les formes élémentaires de la vie religieuse [Las formas elementales de la vida religiosa] (Durkheim, 1985).

${ }^{2}$ Para una revisión más completa de la trayectoria del concepto de secularización, véase mi artículo "Religión y sociología, cuatro décadas alrededor del concepto de secularización" (Blancarte, 2012). 
protesta contra la incertidumbre y el desorden, se podía generar incluso una afinidad electiva entre ciertas formas de religiosidad y la modernidad. Así, para esta socióloga francesa, la secularización no es entonces la desaparición de la religión, "sino el proceso de reorganización permanente del trabajo de la religión en una sociedad estructuralmente incapaz de cumplir o llenar las expectativas que necesita suscitar para existir como tal" (HervieuLéger, 1987: 227).

Ante la ofensiva lanzada por los críticos de la "teoría", algunos autores intentaron sistematizar las diversas posturas existentes. Particularmente exitosa fue la alcanzada por el profesor Olivier Tschannen, quien después de hacer un repaso de las principales posturas académicas, estableció a principios de la década de los noventa del siglo pasado que el paradigma de la secularización se basaba en un núcleo con tres elementos principales: diferenciación, racionalización y mundanización (worldliness):

En el curso de la historia, la religión se vuelve progresivamente diferenciada de otros terrenos de la vida social, emergiendo eventualmente como un terreno institucional específico dentro de un nuevo tipo de estructura social constituido por varias instituciones de ese tipo (educación, política, economía, etc.). Por ejemplo la Iglesia y el Estado se vuelven claramente diferenciados (diferenciación). Al mismo tiempo, las diferentes instituciones no religiosas nacidas de este proceso de diferenciación comienzan a trabajar sobre la base de criterios que están relacionados específicamente a sus funciones sociales específicas, independientemente de cualquier control o guía religiosa. Así por ejemplo, la economía comienza a trabajar de una manera racional dictada por su propia lógica inherente (racionalización). El impacto de esos procesos en la esfera religiosa genera que ésta pierda algo de su especificidad y se vuelva más mundana. Las organizaciones religiosas comienzan a satisfacer las necesidades psicológicas de sus miembros (mundanización). (Tschannen, 1991: 400-401)

De estos tres elementos el más rico en consecuencias es — según este autor- la diferenciación. En ello coincidiría pocos años después José Casanova, en su libro Public Religions in the Modern World, pues allí él sostendría que "la tesis de la diferenciación de las esferas religiosa y secular es todavía el núcleo defendible de la teoría de la secularización" (Casanova, 1994: 7). En esto, Casanova era uno de los primeros, junto con Hervieu-Léger, en plantear que no habría necesariamente una incompatibilidad entre la religión y el proceso que denominamos secularización. Incompatibilidad que, como hemos visto, no plantearon los fundadores de la sociología, pero que fue adoptada equivocadamente como parte esencial del paradigma de la secularización entre los años treinta y setenta del siglo pasado. 
Casanova, sin embargo, a pesar de aceptar que la diferenciación es el núcleo más importante del paradigma, en lo que sería su tesis central, también rechaza la idea de que la diferenciación social moderna "necesariamente conlleva a la marginalización y privatización de la religión", o su lógica contraparte, "que la religión pública necesariamente pone en peligro la estructura diferenciada de la modernidad" (Casanova, 1994: 7). En suma, que si bien podemos reconocer que dicho proceso de diferenciación social existe, eso no significa que la religión deba ser sacada de la esfera pública, porque ese hecho no pone en riesgo el proceso mismo de diferenciación.

La tesis de Casanova es que "somos testigos de la 'desprivatización' de la religión en el mundo moderno". Por desprivatización entiende el hecho de que las tradiciones religiosas en el mundo "se niegan a aceptar el papel marginalizado y privatizado que las teorías de la modernidad, así como las teorías de la secularización, le han asignado" (Casanova, 1994: 5). Al mismo tiempo, sin embargo, Casanova sostiene que "la era de las divisiones religioso-seculares, de las luchas sobre el proceso histórico de la secularización moderna ha llegado a su fin en el área histórica de la Cristiandad Occidental", puesto que las Iglesias estarían aceptando la transferencia de sus particulares privilegios a la persona humana y el principio de libertad religiosa como un derecho humano universal, en lo que él llama, "la transformación de la Iglesia de una institución orientada al Estado a una orientada a la sociedad" (Casanova, 1994: 220).

Es en estos dos aspectos de la tesis de Casanova con los que no estamos de acuerdo, puesto que la experiencia de los años recientes muestra más bien que lo contrario ha sucedido. Ni las Iglesias ni las religiones organizadas parecen estar aceptando la transferencia de sus particulares privilegios a la persona humana, ni el principio de libertad religiosa como un derecho humano se ha realmente universalizado, ni las Iglesias han trasladado el centro de sus preocupaciones y actividades de la esfera del Estado a la de la sociedad civil. Un rápido repaso de la situación mundial nos indica más bien una situación distinta. En América Latina la Iglesia católica, a pesar de la creciente competencia de otras Iglesias cristianas y evangélicas (o quizás por ello), sigue enquistada en el Estado y aprovechando los privilegios aparejados a su hegemonía cultural y política. Las otras Iglesias cristianas (protestantes o evangélicas) de la región, en lugar de perseguir un modelo de mayor laicidad de las instituciones públicas, buscan ahora la equivalencia en los privilegios y el favor del Estado. En el mundo musulmán, la irrupción de los fundamentalismos ha empujado más bien a la constitución de Estados islámicos, muy alejados del modelo secular y de la libertad religiosa para todos. No hay allí ninguna reorientación hacia la sociedad civil. En India, en Israel, en Rusia, en 
Birmania, e incluso en lugares como España y Japón, las religiones tienden a las alianzas con el Estado y a desempeñar un papel identitario que confunde nación y Estado con una religión específica.

Pese a lo anterior, la aportación de Casanova es importante en más de un sentido. El de mayor relevancia para nuestro estudio es por un lado el de identificar el papel central de los procesos de diferenciación, y en segundo lugar el hecho de reconocer la resistencia de las religiones a ser marginadas del espacio público. También, como consecuencia, la posibilidad de identificar procesos mediante los cuales la religión se reinserta en una vida pública esencialmente secularizada, aunque con pronósticos que no necesariamente compartamos. Otra aportación importante de Casanova es identificar, por una parte, el papel del Estado absolutista moderno y la economía capitalista emergentes como elementos esenciales en la transición a la modernidad, y por otra parte señalar a la esfera del mercado o de la economía capitalista como la menos susceptible a la regulación moral. En suma, el texto de Casanova, como antes el de Hervieu-Léger, nos permite entender que la secularización social puede coexistir con la religión. A partir de allí es posible entonces tratar de comprender cuáles son las formas específicas de esta relación, asumiendo incluso que la sociedad atraviesa por un proceso más o menos avanzado de secularización. Pero la religión no ha desparecido; tiene su propia esfera y desde allí intenta recuperar espacios e influencia.

Ahora bien, una de las tesis que aquí queremos desarrollar es que, ante el proceso general de secularización, la religión encuentra esferas en las que es más fácil reinsertarse que en otras, y que la esfera de la política o del Estado es donde históricamente se ha podido reinsertar con mayor facilidad y resistir precisamente a su marginación en el ámbito de lo privado. Siendo la esfera de la política el ámbito donde por esencia se dirime la vida pública, la religión tiende a regresar a ella, por invitación o por presión, desde afuera o desde adentro. De allí que se vuelva central para este propósito revisar el concepto de laicidad.

Al respecto, hay que señalar en primer lugar la existencia de una enorme confusión acerca de los conceptos de secularización y laicidad. El primero suele ser utilizado en los países anglosajones y en general en los de habla inglesa, mientras que el segundo es de uso común en los países latinos, agravado por el hecho de que los franceses inventaron en la segunda mitad del siglo XIX el neologismo "laicidad" (laïcité) y su derivado laïque (separado de la religión), para distinguirlo del vocablo lä̈, de uso frecuente para designar al feligrés común de la Iglesia católica. De hecho, la confusión se inicia desde el momento en que no suelen utilizarse los vocablos equivalentes secularización/laicización; secularidad/laicidad; secularismo/laicismo; secular/laico. 
Para efectos de esta exposición privilegiaremos la pareja secularización/ laicización, pues ésta nos permitirá entender la aparente paradoja del papel de la religión en la era actual.

Veamos entonces las similitudes y las diferencias: la secularización se refiere esencialmente al proceso de diferenciación social, a la racionalización del mundo y de las propias religiones, así como a su mundanización. De manera secundaria, se refiere también a la privatización de la religión y a la reconfiguración de las creencias, impulsadas por la modernidad. Por su parte, la laicización tiene que ver con el proceso general de diferenciación, que genera un movimiento de autonomización de la esfera política respecto a la esfera religiosa, y como consecuencia un esfuerzo de separación de lo religioso respecto a los asuntos públicos.

La laicización podría definirse entonces como el proceso de secularización de la esfera del Estado o de la política, pero también (y esto es central) de los ámbitos de la cultura, la educación y la ciencia, en la medida que éstos se institucionalizan y caen bajo control o supervisión del Estado. Por ejemplo, cuando la educación, privada o pública, pasa a estar bajo supervisión estatal, en la medida que se considera un asunto de interés público. Lo mismo sucede con la ciencia y la práctica médica o en general con la salud pública. En suma, cuando en un área determinada surge el interés "público", se genera, en principio, un proceso de laicización. Es el caso por ejemplo de las cadenas de televisión, cuando son concesiones del Estado, consideradas de interés público, aunque se entreguen a empresas privadas.

El punto relevante en este caso es que, si distinguimos por un lado el proceso general de secularización, el cual incide en el conjunto de las esferas de acción social en las que actúan los individuos y, por el otro, el proceso de laicización, es decir de secularización de la esfera de la política o del Estado, podemos entonces entender la aparente paradoja del mundo contemporáneo: por un lado el proceso de secularización general sigue avanzando, sobre todo en las esferas con mayor inmunidad a las regulaciones morales o religiosas, como es la del mercado o la de la ciencia. Es lo que buena parte de los especialistas, como Ronald Inglehart, Steve Bruce o Pipa Norris, siguen registrando, particularmente en las sociedades más desarrolladas, aunque también en otros lugares. Por el otro, la religión "regresa" (si alguna vez se fue) a la esfera política. Todo lo cual genera una tensión social y política que se resuelve de manera diversa en el mundo, de acuerdo con las trayectorias históricas específicas de cada país.

El esquema gráfico del proceso de diferenciación social sería entonces el siguiente: 


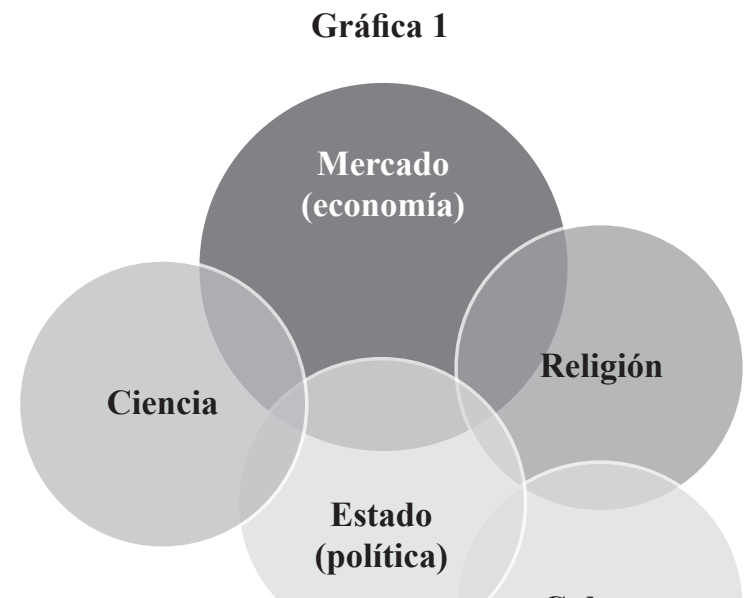

Cultura

En este esquema se aprecia claramente el proceso de diferenciación social y gestación de esferas autónomas de acción, existente en todas las sociedades modernas. Asumimos en el mismo que, salvo por el tamaño del mercado, el cual es central en el proceso de secularización, las otras esferas son prácticamente iguales. Sin embargo, dependiendo del caso, tendríamos un mercado más pequeño y un Estado más grande (por ejemplo en Cuba). En otros lugares, el mercado sería mayor y el Estado relativamente menor, con una esfera religiosa más importante (por ejemplo en Estados Unidos de América). La esfera religiosa podría ser más pequeña (por ejemplo en Francia o en Suecia) o más grande (por ejemplo en Irán o en Arabia Saudita).

Lo que aquí queremos resaltar es por un lado la existencia de un proceso general de secularización, en el conjunto de la sociedad frente a procesos de secularización específicos en las diversas esferas, los cuales pueden ser por diversas razones menos o más avanzados que dicho proceso general. Así podemos tener, por ejemplo, que por razones muy específicas en una determinada trayectoria histórica la esfera de la cultura tenga más influencia religiosa y se generen procesos de identidad cultural o nacionalismos influidos por una determinada Iglesia o religión, independientemente de que el proceso de secularización siga avanzando. Países como Grecia, Argentina o India serían un claro ejemplo de este fenómeno. Lo mismo puede suceder con la 


\section{Gráfica 2}

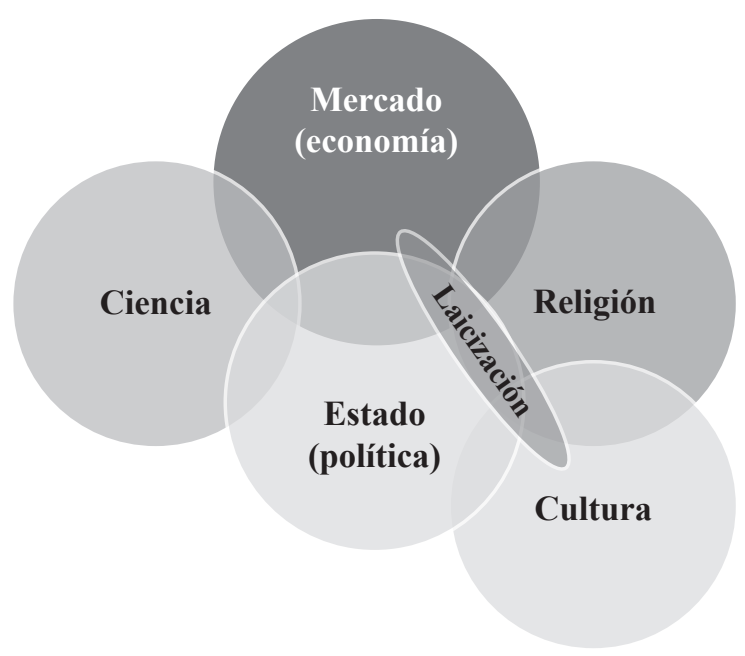

esfera de la política, si tenemos procesos débiles de laicización del Estado, porque la religión ha invadido la esfera pública de diversas maneras. Es el caso de países como Israel o Brasil, donde la laicización del Estado no parece caminar con la misma velocidad que la secularización en el resto de las esferas sociales. Lo contrario también puede ser cierto, es decir, que los procesos de laicización del Estado (en la esfera política) sean más avanzados que los de otras esferas. Fue el caso de los países soviéticos de Europa del Este o de Cuba, pero también de la actual Bolivia o de Venezuela, donde por razones políticas coyunturales los procesos de laicización del área política se adelantan a los de secularización del resto de la sociedad. Lo que sucede entonces entre las esferas religiosa y política puede tener una dinámica muy diversa a la impresa en el conjunto de la sociedad por el proceso de secularización.

El otro punto esencial en este esquema (y que podemos apreciar en la gráfica 2), es que nos permite ver la existencia de intersecciones entre las diversas esferas. En otras palabras, lo que definimos en términos generales como los procesos de secularización y de laicización —en el sentido de una autonomía creciente de las otras esferas de acción respecto a la religiosa y la creación de principios y valores específicos para cada una de estas áreas - no es un proceso acabado ni absoluto, en el que las esferas de acción están com- 
pletamente delimitadas. Existen de hecho intersecciones que muestran zonas de influencia mutuas. Y es precisamente allí donde se "reintroduce" (en el caso de haber sido expulsada) la lógica religiosa, que vuelve a colonizar, con mayor o menor éxito, el pensamiento político secularizado. Éste pudo haber alcanzado algún grado de autonomía y sin embargo, por razones diversas, la religión vuelve a ganar espacios y a influir nuevamente en dicha esfera, que es la de la acción política y por lo tanto donde en muchas ocasiones se definen políticas públicas. De allí que el "regreso" de la religión a la vida pública sea tan ostentoso y muchas veces dramático: afecta directa e inmediatamente la vida de las personas, incluso aquellas que están normalmente alejadas de la vida política.

Lo que Casanova señaló como la "desprivatización de lo religioso" tenía para él como resultado "un proceso interrelacionado dual de repolitización de las esferas morales y religiosas privadas y la re-normativización de las esferas política y económica públicas". Para él,

Las religiones a lo largo del mundo "están entrando en la esfera pública y la arena de la contestación política no sólo para defender sus enseñanzas tradicionales, como han hecho en el pasado, sino para participar en las luchas para definir y establecer las fronteras entre las esferas pública y privada, entre el sistema y el modo de vida, entre legalidad y moralidad, entre individuo y sociedad, entre familia, sociedad civil y Estado, entre naciones, Estados, civilizaciones y el sistema mundial". (Casanova, 1994: 6)

Para este autor no se trata de poner en cuestión el paradigma de la secularización, o de eliminar las fronteras entre lo público y lo privado "que son necesarias para proteger las libertades modernas y estructurar a las modernas sociedades diferenciadas". Lo que está en juego — nos dice Casanova- “es la necesidad de reconocer que las fronteras mismas están abiertas y necesitan estarlo a los cuestionamientos, redefinición, renegociación y legitimación discursiva" (Casanova, 1994: 65).

Para Casanova era importante afirmar que por un lado habría una legítima resistencia religiosa a las perspectivas seculares del mundo, la cual constituye más que un rechazo a aceptar las consecuencias de la Ilustración; y que por el otro hay una legítima resistencia de las religiones a la des-politización, que constituye algo más que un aferrarse a privilegios heredados (Casanova, 1994: 38).

Aunque no estemos de acuerdo con los supuestos filosóficos de esta postura, pues habría que aceptar que las religiones han asumido los principios de la modernidad, o con la idea de que hemos llegado al fin de las divisiones religioso-seculares por una supuesta transformación y reorientación de las Igle- 
sias del Estado hacia la sociedad civil, ${ }^{3}$ nos parece importante retomar la consideración de la redefinición de las fronteras no sólo entre lo público y lo privado, sino entre las diversas esferas públicas o privadas de la acción social, como pueden ser la cultura, la educación, la ciencia, la economía y por supuesto la política y la religión.

Lo importante, para efectos de nuestra investigación, no es por lo tanto si las creencias religiosas aumentan o disminuyen, o si la influencia social de la religión ha cambiado. Tampoco es si la religión fue privatizada y alejada de la esfera pública; lo cual también volvería irrelevante saber si está regresando a la esfera pública (es decir se está desprivatizando), o si alguna vez realmente se fue de ésta. Nuestro objetivo es más bien observar las áreas de intersección (que va más allá de lo que Casanova quizás definiría como las fronteras cambiantes) entre las diversas esferas, de tal manera que podamos reconocer dos cuestiones esenciales: las distintas "velocidades" que se dan entre el proceso general de secularización (en el conjunto de la sociedad) y el de laicización (entre las esferas religiosa y política).

Entenderíamos así que la secularización y la laicidad son dos conceptos que muestran diferentes aspectos de un proceso dinámico de continua redefinición de las esferas (diferenciadas) de lo social (educación, cultura, economía, ciencia, etc.), así como de lo político y lo religioso.

Así, mientras que la secularización se relaciona con el proceso general de diferenciación social, la laicidad se relaciona con el trabajo permanente de negociación entre la esfera de lo político (donde predomina el Estado) y la esfera de lo religioso. Este proceso permanente de negociación y renegociación sucede en el espacio creado por la intersección entre las esferas política y religiosa, y no es incongruente con el creciente trabajo de secularización avanzado por otras esferas, particularmente la del mercado (la economía). De la misma manera que pueden moverse incluso en sentido contrario: sociedades más secularizadas pueden conocer retrocesos en sus procesos de laicización, o viceversa. Con este enfoque podríamos explicar por qué las religiones aparecen perdiendo terreno en muchos ámbitos de la sociedad, al

${ }^{3}$ De hecho, Casanova mismo, al final de su libro, señala que él estaría de acuerdo con "que sólo una religión que ha incorporado como propios los aspectos centrales de la crítica ilustrada de la religión está actualmente en una posición para desempeñar un papel positivo en el avance de los procesos de racionalización práctica". Y reafirma: "Sólo una tradición religiosa que reformula su relación con la modernidad, incorporando reflexivamente las tres dimensiones de la crítica de la religión ilustrada - la crítica cognitiva de las visiones del mundo religiosas tradicionales, la crítica práctica-moral de las ideologías religiosas de legitimación y la crítica expresiva-subjetiva del ascetismo y alienación religiosa - al mismo tiempo que se sostienen públicamente los valores sagrados de la modernidad, es decir la vida humana y la libertad, puede contribuir a la revitalización de la esfera pública moderna" (Casanova, 1994: 233). 
mismo tiempo que ganan terreno en los espacios políticos. $\mathrm{O}$, dicho de otra manera, por qué, a pesar de que las sociedades se están secularizando, las religiones están "regresando" a la esfera pública.

Muchas razones son las que se han avanzado para explicar este fenómeno: el propio éxito del Estado de derecho y el pluralismo cultural, las ideologías paseístas de la identidad y de la comunidad, la posición privilegiada de las organizaciones religiosas en medio de la crisis de crecimiento de la ciudad contemporánea, la crisis de legitimidad de las instituciones políticas, el debilitamiento de las utopías de la modernidad, la necesidad de nuevos sentidos existenciales, etcétera. ${ }^{4}$ En cualquier caso, me parece que hay que adelantar un elemento central de la estructura misma del proceso de laicización: la intersección entre política y religión permite la renegociación permanente y en este espacio, en virtud de la acción política misma, es mucho más simple revertir el proceso de secularización. Los actores están más dispuestos a redefinir las esferas porque la política lo permite e incluso lo empuja, mientras que las otras áreas de secularización suelen ser más rígidas. La esfera de la ciencia, por ejemplo, permite poco espacio de negociación con las creencias religiosas, pues se rige por principios propios difíciles de negociar. Lo mismo sucede con el mercado, cuyos principios rectores suelen ser impermeables a consideraciones religiosas. Hay, sin embargo, esferas que por su estructura y principios hacen posible la negociación con lo religioso. Es el caso de la esfera de la cultura, debido a consideraciones antropológicas (tradiciones, tendencias de largo plazo) e identitarias. De la misma manera, la política, en la medida que es negociación pura y tiene como principio rector el del poder, fácilmente puede incluir elementos no seculares de legitimación del mismo.

La paradoja de la secularización y el retorno de la religión a la esfera pública se resuelve de esa manera: la laicización de la esfera del Estado, es decir de la política, puede avanzar a otra velocidad e incluso en contrasentido al proceso de secularización social general. No siempre hay congruencia entre los diversos subsistemas de dicho proceso y eso hace posible que la religión se resista a ser desalojada o regrese a los espacios que durante algún tiempo y en algunos lugares del planeta le han sido vedados. La esfera de la política, que de por sí tiende a sacralizarse, suele aceptar con gusto, mediante un proceso de renegociación permanente y de búsqueda de legitimación, que la religión sea parte de su fundamento. Todo lo cual genera tensiones, mismas que estamos observando en muchas regiones del planeta.

\footnotetext{
${ }^{4}$ Véase al respecto el texto de Jaques Zylbelberg (1995), "Laïcité: connais pas: Allemagne, Canada, États Unis, Royaume Uni”.
} 
Recibido y revisado: mayo de 2015

Correspondencia: Centro de Estudios Sociológicos/El Colegio de México/ Camino al Ajusco núm. 20/Col. Pedregal de Santa Teresa/C.P. 10740/México, D.F./correo electrónico: blancart@colmex.mx

\section{Bibliografía}

Blancarte, Roberto (2012), "Religión y sociología, cuatro décadas alrededor del concepto de secularización”, Estudios Sociológicos, vol. XXX, número extraordinario, pp. 59-81.

Casanova, José (1994), Public Religions in the Modern World, Chicago y Londres, The University of Chicago Press.

Durkheim, Émile (1985), Les formes élémentaires de la vie religieuse, 7a. edición, París, Presses Universitaires de France.

Hervieu-Léger, Danièle (con Françoise Champion) (1987), Vers un nouveau christianisme?; Introduction à la sociologie du christianisme occidental, 2a. edición, París, Éditions du Cerf.

Tschannen, Olivier (1991), "The Secularization Paradigm; a Systematization”, Journal for the Scientific Study of Religion, vol. 30, núm. 4, pp. 395-415.

Weber, Max (2014), Economía y sociedad, nueva edición revisada, comentada y anotada, México, FCE.

Weber, Max (1988), Gesammelte Aufsätze zur Religions-soziologie, 3 vols. [traducidos al español como Ensayos sobre sociología de la religión, Madrid, Taurus, 1998].

Zylbelberg, Jaques (1995), "Laïcité: connais pas: Allemagne, Canada, États Unis, Royaume Uni”, Pouvoirs, Revue Française de Études Constitutionelles et Politiques, núm. 75, noviembre, pp. 37-51.

\section{Acerca del autor}

Roberto J. Blancarte es doctor en Historia y civilizaciones por la Escuela de Altos Estudios en Ciencias Sociales, en París, Francia. Actualmente es profesor-investigador del Centro de Estudios Sociológicos de El Colegio de México, del cual fue director de enero de 2006 a marzo de 2012. Sus principales líneas de investigación son religiones y creencias en el mundo moderno, laicidad y secularización y relaciones Iglesia-Estado. Recientemente ha publicado "El papel del Estado laico en el desarrollo de los derechos sexuales y derechos reproductivos en América Latina", en Daniel Gutiérrez y Karina Felitti (coords.), Diversidad, sexualidades y creencias: los derechos 
del cuerpo en el mundo contemporáneo, México, El Colegio Mexiquense, 2015; "Le Mexique, une République laïque: fin du chemin ou début des débats?", en Jean Baubérot, Micheline Milot y Philippe Portier (eds.), Laïcité, laïcités, reconfigurations et nouveaux défis, París, La Fondation Maison des Sciences de l'Homme et Le Centre d'Études Éthniques des Universités Montréalaises, 2014, pp. 281-307; así como Religión, laicidad y biopolítica, México, El Colegio de México y UNAM, 2013. 
